\title{
Peertechz
}

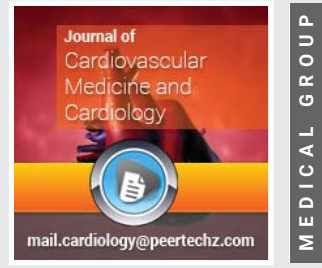

\section{Primary chronic septic} endocarditis as an alternative to acute rheumatic fever - the obligate component of the multicomponent noncyclic pandemic of the $21^{\text {st }}$ Century

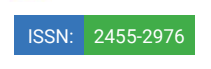

\author{
GM Bushmanova*, MV Supotnitskiy and BV Churin \\ Institute of Molecular Pathology and Pathomorphology of the Federal Research Center of \\ Fundamental and Translational Medicine, Novosibirsk, Russia
}

\begin{abstract}
Received: 29 May, 2020
Accepted: 10 August, 2020

Published: 12 August, 2020

*Corresponding author: GM Bushmanova, Institute of Molecular Pathology and Pathomorphology of the Federal Research Center for Fundamental and Translational Medicine, Mikhail Ivanovich Voevoda, Russia, Tel: 8-913-70-15-43; E-mail: gbushmanova37@mail.ru

ORCID: https://orcid.org/0000-0002-5012-5608

Keywords: Alternative; Group A beta-haemolytic streptococcus; Aschoff-talalaev granuloma; Microbiome; COVID-19; Multicomponent noncyclic infection; Pandemic; Primary chronic septic endocarditis; Acute rheumatic fever; Sterile complication
\end{abstract}

https://www.peertechz.com

Check for updates

\section{Introduction}

The concepts of acute rheumatic fever [1-3] and septic endocarditis (according to the International Classification of Diseases, is called infectious endocarditis. Septic endocarditis is the principal author's standpoint) - diseases that are still considered the main causes of acquired heart defects in Russia, have been under discussion for many years. The main question pertaining to this is the "specificity" of its pathogen. The opinion about the strict nosological independence of diseases, established in the late 60s, was questioned in the early 80 s.

The clinically unusual form of septic endocarditis - primary chronic septic endocarditis [4] - which was first identified by us (Galina Bushmanova) in patients with acquired heart defects towards the end of 1979 , was a serious basis for the subsequent long-term study of the key aspects of the problem (1980-2020) [5-14]. The disease's unusual clinical manifestations, which allowed it to be associated with primary chronic inflammation, served as an opportunity for positioning the disease as a "new" clinical phenomenon of the 20 th and $21^{\text {st }}$ centuries, disguised as acute rheumatic fever.

We proposed a pentad of extracardiac pathognomonic symptoms for both diseases, which solved the problem of early diagnosis in the prevalvular, isolated parietal stage [15-17]. This made it possible to conduct long-term studies focused on the natural course of the disease with its features, stages and progression trends [18-24]. The existence of primary chronic septic endocarditis has been proven using all available methods of modern cardiac surgery and pathomorphology, including the use of a scanning electron microscope $[6,10,13]$. The results of a long-term prospective study of patients at early prevalvular stages within the periods exceeding 20 to 30 years confirmed the accuracy of diagnostic criteria and the existence of primary chronic septic endocarditis.

However, in connection with the results obtained, a question arose about the key aspects of the acute rheumatic fever and septic endocarditis problems.

The purpose of this work is to present an analysis of the key aspects of acute rheumatic fever, from the standpoint of their evidentiary significance, in relation to the disease traditionally associated with the "sterile complication" of infection that is associated with Group A Beta-Haemolytic Streptococcus comparing them with the results concerning septic endocarditis.

\section{Material and methods}

The material is the result of our long-term study (1980-2020) of primary chronic septic endocarditis (G.M. Bushmanova, 1979) $[4,13]$. The pre-surgery clinical diagnosis of this condition in patients with comorbid acquired valvular disease, established upon the identification of our proposed extracardial pathognomonic markers of primary chronic septic 
endocarditis, constituted the main diagnostic pentad [15-17], as previously reported. This was confirmed by the results of intrasurgery studies, including morphological ones. The latter was carried out by V.A. Gross [6]. A total of 1962 operated patients with acquired heart defects were examined. Using scanning electron microscopy, the researcher studied biopsy and autopsy material of valves resected during surgery from 73 patients. The clinical study was supplemented with a wide range of methods available in modern cardiac surgery and pathomorphology: macro- and histomorphological, bacteriological, bacterioscopic, cytological, and immunohistochemical methods. P.M. Larionov studied morphological changes in internal organs in this pathology [25]. The patent "Method for the diagnosis of bacterial endocarditis" [8] was received. Studies for blood parasitic infection in 42 patients were performed by A.V. Terletsky and L.G. Akhmerova, who received the patent "Method for the diagnosis of blood parasitic infection" [26]. Echocardiographic studies were performed by I.G. Zorina.

Primary chronic septic endocarditis, as the further studies showed, can be present under the guise of acute rheumatic fever $[10,13]$. In this regard, it seems that our earlier results serve as the basis for a revolutionary change in the existing paradigm of this disease, which is responsible for acquired heart defects. Further, it is suggestive of a need for change in the "generic" concept of "rheumatoid" to "chroniosepsy", with a corresponding change in the main pathogenetic directions of the therapeutic strategy.

In this regard, several questions arise. How unexpected was this result? What does the data about acute rheumatic fever look like from the perspective of evidence-based medicine? What new information has become available in recent years that would allow considering the opinion that it is a nosologically independent and highly specific disease, inextricably linked with Group A Beta-Haemolytic Streptococcus, to be reasonable and justified? Key aspects of acute rheumatic fever were analyzed to answer these questions. The results of our own targeted research and literature data concerning these aspects were used.

\section{Research results and discussion}

As our previous studies showed, primary chronic septic endocarditis showed the true face of acute rheumatic fever - a disease with a long history, which at the initial stage was the subject of close attention of the world scientific community. The "new", unusual form of the old disease seemed to be a possible alternative to acute rheumatic fever. Acute rheumatic fever and primary chronic septic endocarditis were associated as antipodes with significantly different characteristic, which form genesis of each of these diseases. So, according to the popular opinion, acute rheumatic fever seemed to be a "sterile complication" of Group A Beta-Haemolytic Streptococcus. It was this position that served as a reference in the differential diagnosis. The modern theory about acute rheumatic fever is not deliberately discussed.

We are basing this on the belief that the primary chronic septic nature of the disease is responsible for acquired heart defects, which can be presented in all manifestations from clinical and paraclinical to morphological. We see the only possible explanation for this disease as being a result of intrapartum transplacental genesis. The results of our research show that today's modern scientific doctrine focuses on the secondary mechanisms of pathology formation that are characteristic of the later stages of the disease (immune response, systemic autoimmune inflammation, and others). At the same time, attention is not paid to the core issue the nature of the disease. Is endocarditis, septic or aseptic, a "sterile complication" of Group A Beta-Haemolytic Streptococcus? This was a hypothesis taken on faith, with autoimmune inflammation undeservedly placed at the forefront.

Based on the transplacental genesis of primary chronic septic endocarditis we have assumed that before the development of the immune response to the pathogen while the pathology is formed, a certain, sometimes considerable, period of time passes. While in the body of a pregnant woman, the pathogen becomes "native" to her body. During this period, the immune system is not able to differentiate "self" from "other". The birth of a child, apparently, can be considered the starting point of the development of nosological characteristics of primary chronic septic endocarditis. It seems logical to associate this period with a long-term lack of an immune response to the pathogen that is stimulated after a period of intrauterine "sleep". Only over time, as the pathogenic and immunogenic potential increases, the pathogen acquires the ability to induce an immune response to it, with the resultant development of systemic inflammation.

When addressing key aspects of acute rheumatic fever, the following data was obtained:

*An experimental model of acute rheumatic fever has not yet been created, and an attempt to reproduce the disease in animals was made by representatives of the school of the famous domestic rheumatologist G.D. Zalessky (1902-1966). He was the author of the hypothesis of the viral streptococcal nature of rheumatism, and the attempt resulted in a model of the infectious-pyemic variant of sepsis, the highest expression of non-specific inflammation $[27,28]$.

*The absence of an experimental model of acute rheumatic fever was the reason for the lack of scientific understanding of its pathogenesis. The supposed strict specificity with respect to Group A Beta-Haemolytic Streptococcus comes into conflict with Koch's postulates concerning the specificity of the pathogen [7].

*The scientific interpretation of the essence of the Aschoff-Talalaev granuloma by clinical rheumatologists and morphologists does not coincide. The latter excludes its belonging to systemic immune inflammation, regarding it as local, such as delayed hyperresponsiveness, not as immune granuloma of foreign bodies with toxic effects because of the remaining streptococcus membranes [29-31]. In this way, a pathogen has actually been recognized thus excluding the "sterility" of granulomas and indicating its belonging to sepsis. This is confirmed by the detection of the coccoid microbiota 
in the Aschoff-Talalaev granuloma and its environment during the study on the Scanning Electron Microscope. Thus, the Aschoff-Talalaev granuloma, which was considered a pathognomonic (absolute) histomorphological phenomenon of the disease called acute rheumatic fever, by its 115th anniversary, had turned from an argument "for" it into an absolute counter-argument "against" it. It is fundamentally important to understand that granulomatous, i.e. primary chronic inflammation, is causally associated with viruses or rickettsia. This is something that must be taken into account in the process of searching for a real-life key to understanding the essence of this mysterious disease.

*There is still no reliable diagnosis of acute rheumatic fever, despite its diagnostic criteria having been repeatedly reviewed by WHO experts. Hyperdiagnosis of acute rheumatic fever, regarded by Professor V.N. Anokhin as "inconsistent with WHO criteria", which turned out to be equal to $50 \%$ (with primary rheumatism) and $80 \%$ (with recurrent rheumatism) when recounted, did not attract attention of rheumatologists [32]. It is important to bear in mind that WHO criteria only allow for provisional, not reliable, diagnosis. At the same time, an even higher percentage of overdiagnosis by the clinic's specialists, which is the historical cradle of Russian rheumatology, suggesting the work of highly qualified rheumatologists, is not excluded. Criteria are, thus, not the case, and the reason behind this phenomenon should be more deeply sought. V.N. Anokhin, taking into account the results of a retrospective review of the acute rheumatic fever diagnosis (920 cases), in his report at the First Congress of Rheumatologists of Russia, drew attention to the "relative suitability" of the WHO criteria for both primary and palindromic rheumatism, emphasizing that they will not replace the creative approach, and the doctor's experience. He suggested that the criteria should be reviewed again.

According to one of the founders of Russian rheumatology, academician A.I. Nesterova (1895-1979), "Jones's criteria were never intended to replace the doctor's wisdom and prudence." It is noteworthy that Jones himself did not insist, unlike A.A. Kissel (1859-1938), on the pathognomonicity of the markers he proposed, urging doctors to look for other diseases when they are detected. Probably, the scientist was afraid to overestimate their diagnostic significance.

*Pathogenetic therapy for acute rheumatic fever, due to the lack of strict scientific understanding of pathogenesis, is impossible. The widely used salicylates and non-steroidal antiinflammatory drugs are among the reversible and irreversible indirect immunosuppressants, the use of which at first was accompanied by a false positive effect, which give experts false ideas. The so-called "anti-rheumatic" therapy, which was applied for many years, being symptomatic, could not prevent acquired heart defects. Moreover, there is a reason to believe that acquired heart defects were developed because of such a therapy.

As is widely known, bicillin and its modern analogues are among the repository medicines that do not provide a constant concentration of an antibiotic in the body, which could contribute to pathogen selection. The lack of preventive measures when using probiotics contributes to dysbiosis (gut microbiota imbalance), which negatively affects immunity. Given that taking antibiotics, especially penicillins, can lead to the development of fungal superinfection, patients need targeted monitoring and, if necessary, antimycotic therapy, which, as a rule, was not taken into account.

*Taking into consideration all of the above mentioned, it is impossible to prevent the disease.

Today, acute rheumatic fever has been studied over a long period of time, but no evidence in favor of its nosological independence as a sui generis disease has been discovered. Moreover, when using a scanning electron microscope, a coccoid microbiota was found in Aschoff-Talalaev granuloma, which proves its non-specificity. Also, septic endocardial damage was observed. Against this background, "rheumatogenic" M-proteins - M-5, M-6, M-18, M-24 [3] and the discovery of a genetic marker of predisposition to acute rheumatic fever cannot but cause bewilderment. It seems incorrect to try at any level, including morphological (Aschoff-Talalaev granuloma) and genetic, to talk about possible diagnostic markers and criteria for a disease that does not actually exist.

In contrast to the foregoing, the key aspects of primary chronic septic endocarditis, which have been studied for over $\mathbf{4 0}$ years in one of the leading centers for cardiovascular surgery in Russia, the Novosibirsk Research Institute of Blood Circulation Pathology named after E. N. Meshalkin, now the Federal Research Center named after Academician E.N. Meshalkin, and then continued at the Research Institute of Regional Pathology and Pathomorphology SB RAMS (which is now called the Institute of Molecular Pathology and Pathomorphology of the Federal Research Center of Fundamental and Translational Medicine), can be characterized as follows:

**Preoperative chronic septic endocarditis in patients was confirmed intraoperatively, before admission to the Department of Septic Endocarditis, which was treated at their places of residence for rheumatism. I.e., it is confirmed that chronic septic endocarditis, for which so-called acute rheumatic fever was mistaken, exists. With the use of a scanning electron microscope, coccal microbiota were detected in the cells of the Aschoff-Talalaev granuloma and in its environment, which indicates the non-specific inflammation, and its infectious nature. This dispels the myth of the strict specificity of this phenomenon. During the surgery on acquired heart defects, bacteriological examination of 883 different biosubstrates were found in 528 patients with the following high microbial infection: valve $-82 \%$, pericardium $-72 \%$, blood culture from the left heart $-68 \%$, left atrium , atrial appendage $-64 \%$, thrombus $-61 \%$, and pleura- $60 \%$. In the etiological structure of the disease, $75 \%$ were Staphylococcus epidermidis and Staphylococcus aureus. Positive blood culture before surgery was $64 \%$ and $75 \%$ in different samples.

As was shown earlier [13], all methods available to modern cardiac surgery and pathomorphology were used to verify the preoperative diagnosis, which ensured the high reliability of the results. 
It is noteworthy that the founder of clinical medicine, the author of the theory of the chronioseptic nature of rheumatism, N.D. Strazhesko (1876-1952) drew attention to the fact that several researchers (Reye, Salus, Krogius, Siegmund, etc.) reported on the detection of virulent streptococci on the endocardium in patients with rheumatic heart disease [33]. These data indicate that many years ago, an attempt was made to directly study the nature of endocarditis by obtaining evidence of its septic nature. Unfortunately, this did not prevent the teachings of the outstanding scientist, whose high professionalism and talent allowed him to be ahead of his time by almost a century, to undeserved oblivion for many years. At present, many years later, one can speak of the triumph of the ideas of the great diagnostician, academician N.D. Strazhesko! The new data obtained by us today completes the clinical portrait of the disease, highlighting new sides of this, which still remains mysterious, phenomenon.

**The experimental model of the disease has been reproduced repeatedly. The researchers of our Institute A.M. Belyaev and P.M. Larionov received a patent for the invention "A method for modeling infective endocarditis" during our experiment [34].

**Along with the clinical and morphological manifestations of the disease, this made it possible to develop an idea of pathogenesis. It belongs to an endogenous infection (III, septic stage, according to the classification of A.F. Bilibin (18971986)) against the background of dysbiosis and reducing the nonspecific resistance of the body (immunodeficiency) [35] One of the clinical manifestations of which was primary chronic septic endocarditis. Histomorphological manifestations, in the form of proliferative mononuclear-infiltrative inflammation, suggest that the nature of the disease in the form of systemic septic (nonspecific) endovasculitis is viral. However, the primary chronic nature of the accompanying inflammation, in combination with a high epidemic threshold and the detection of the disease in 3 generations (child <mother < grandmother) suggest an intranatal transplacental genesis. It occurs due to the transmission of the pathogen against the background of physiological gestational immunosuppression. The placenta is transformed from an organ that should physiologically protect a developing fetus from infection, into the nidus of infection [36].

Along with this, blood parasites, such as Babesia of the genus Piroplasma of the family Babesiidae with a frequency of up to $100 \%$ with parasitemia within $39.4 \%$ and $29 \%$ in different samples (93\% in the Russian Federation), Bartonella with frequency (82\%), Riketsia (15\% and 50\% in different samples) were discovered in these patients, and their role and place in this pandemic multicomponent non-cyclic process requires clarification. This invasive zooanthroponic pathology, which overcame the species barrier, and which has been discussed by by A.V. Terletsky and L.G. Akhmerova for several years, deserves in-depth study, to determine its possible role in the genesis of many diseases that are currently considered somatic [37-39]. What contribution can babesia invasion make to the current pandemic of endogenous sepsis? There is no doubt that in parallel there is a latent pandemic invasion caused by bloodsuckers, which claim their permanent representation in the human and animal body.

** Knowledge of pathogenesis opens up the possibility of etiological and pathogenetic therapy, which is accompanied by a positive clinical and laboratory effect, counteracts the disease's progression and inhibits acquired heart defects [1824]. It meets the requirements of preventive medicine.

**Early diagnosis is provided, because the hierarchy of diagnostic priorities, including Duke Criteria, were revised. The extracardial symptoms that we have identified become a priority. These are, namely, the pentad of clinical markers of P-cholesterol and endocarditis, the pathognomonicity of which is proved by the results of intraoperative verification of the diagnosis and long-term (over 20-30 years) prospective observation of patients in early stages, including isolated parietal endocarditis [18-24]. Figure 1 shows a cardinal, pathognomonic (absolute) symptom of primary chronic endocarditis and sepsis - conjunctival necrosis, which occurs in patients with acquired heart defects in $80 \%$ of cases. It should be noted that alignment with the Duke Criteria, as the main necessary stage of the diagnostic process, is associated with a loss of necessary clinical primacy in the diagnosis of the disease. This is instead of a priority linked to laboratory and instrumental research methods, the result of this disease's late diagnosis. It should also be noted that Durack, the author of the Duke Criteria, proposed them for epidemiological research, and not for the early diagnosis of septic endocarditis. This must be borne in mind in order to represent the true level of diagnostic capability that these criteria hold.

Early diagnosis made it possible to conduct long-term prospective observation of patients in the early stages, and to monitor its natural development, revealing the features, stages and trends of progression. The obtained results make up for the missing section of ideas concerning the early periods of the disease, which is today called septic endocarditis.

The priority in diagnostics was given to clinical diagnostics. The pentad of clinical markers of pathology that are extracardiac and pathognomonic is represented by two minor syndromes:

\section{Microthromboembolism}

- Necrosis on the eyelid conjunctiva, which we consider as evolutionary variants of the classic pathognomonic symptom for septic endocarditis - Lukin-Libman's (Rot) spots;

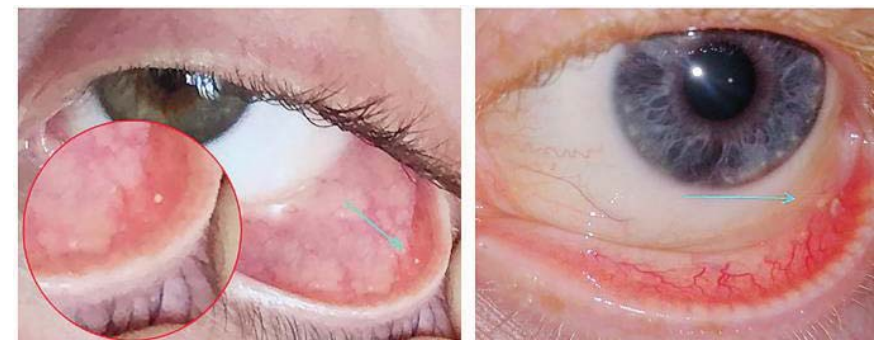

Figure 1: Cardinal, pathognomonic symptom of primary chronic endocarditis and conjunctiva's necrosis- sepsis. 
- Spontaneous subungual hemorrhages that look like splinters.

Small vesicular rashes on the skin and mucous membranes:

- Small vesicular enanthema of the hard palate is closer to the soft palate;

- Small vesicular exanthema of the skin, mainly of the hands and feet, often accompanied by itching;

- Elements of small focal atrophy or hypertrophy of the skin, sometimes accompanied by mild itching. The frequency of symptoms in patients with acquired heart defects is as follows: $80 \% ; 54 \% ; 86 \% ; 24 \% ; 30 \%$. Elements of the latter syndrome, presumably in genesis, are associated with viruses. These symptoms can be observed in the early stages of the disease, sometimes being the only manifestations of a latent disease. This gives them strategic value.

The early echocardiographic diagnosis of primary chronic septic endocarditis is of particular interest. It is a reflection of the characteristic primary chronic inflammation which is structurally expressed as fibrosis. Disguised as the latter, in the presence of a low-virulent pathogen, the flat vegetations can be hidden, which are visualized only during SEM. This was shown by us earlier [40-43].

Prospective studies were conducted, along with echocardiographic monitoring. This allowed the establishment of the structural features of the disease, and its progression trends [18-24]. It should be emphasized that the dynamics were observed against the background of periodical treatment. This helps to make it possible to restrain heart defects and the increase in hemodynamic significance, which requires surgery. It has been established that the main structural feature of the disease is fibrosis. Its progression is accompanied by the gradual involvement of the valve endocardium, more often in the stereotypical sequence: MK.> AK> .TK, with a gradual expansion of the area of damage, at the expense of endocardial extravalvular structures (subvalvular chords, heads of papillary muscles, interventricular septum, moderator bundle of the right ventricle, and ventricular wall). Over time, endocardial fibrosis increases and becomes more diffuse. Against this background, the area of the valve, when it is open, is reduced, and stenosis is formed.

Since primary chronic septic endocarditis is a manifestation of systemic vasculitis, fibrosis will first capture local areas of the vascular system. This is accompanied by local stenosis in the brachiocephalic, coronary, renal, femoral and other arteries. At the same time, progressive fibrosis of the endocardium and blood vessels gradually cause systemic organosclerosis, which triggers an organ's acquired pathology and chronic cardiac insufficiency. The observed dynamics of the echocardiological features of the sequential development of the disease is reflected in the previously presented clinicalmorpho-topographic classification [44].

Thus, the right to exist as an independent sui generis disease lost by acute rheumatic fever seems to be non-accidental, as evidenced by the analyzed key aspects. An alternative to acute rheumatic fever is primary chronic septic endocarditis, the existence of which is absolutely proven.

In addition, over the past decade, foreign scientists have acquired unprecedented results during the implementation of the Global International Project "Human Microbiome" which was the continuation of the "Human Genome" project. They discovered a microbiome in the female reproductive system, including the placenta. This is real evidence of its infection. The same goes for the male reproductive system, breast milk and blood! [45-54]. We are talking about the total infection of a person. Reproduction in such critically threatening conditions creates serious problems for modern obstetrics and neonatology, the overcoming of which is real heroism.

\section{Conclusion}

This study's results indicate that acute rheumatic fever has lost its right to nosological independence sui generis (which was proved by our previous works), not by chance. It was based on the absence of an evidence base for the basic postulates of its scientific doctrine. An alternative to acute rheumatic fever is a universal systemic primary chronic nonspecific septic endovasculitis and its complication - an obligate component of a multicomponent non-cyclic pandemic of the $21^{\text {st }}$ century (MV Supotnitskiy) [55-58].

It is possible to consider the data mentioned above to confirm our ideas about the ongoing pandemic of endogenous sepsis. Primary chronic septic endocarditis is one of its clinical complications. This is a mandatory component of a pandemic multicomponent non-cyclic infection, the ideas about which are associated with the name of the famous Russian microbiologist M.V. Supotnitskiy [55-58].

Considering foreign scientists' unique data on DNA sequencing various human biotopes; we can state that our concept of primary chronic septic inflammation, in an endogenous sepsis pandemic (G.M.Bushmanova), has been confirmed at a high metagenomic level.

Thus, one of the oldest diseases of mankind - sepsis, incurable even with the triumph of antibiotic therapy, today demonstrates its new facet in the form of primary chronic sepsis and its complication - primary chronic septic endocarditis. Apparently, nature threw us a trial balloon in the form of a large-scale epidemic (pandemic) in the form of endogenous sepsis. It is not yet realized by representatives from the global medical community. It is testing humanity's strength and readiness to face an even more formidable enemy. The current multi-component non-cyclical pandemic has been enlarged by the COVID-19 pandemic, which has made the world shudder from a new awareness in the inevitability of global catastrophe [59]. Being confidently presented by a tandem of various representatives from the viral-bacterial-protozoal microworld, this has an unpredictable destructive potential. But, it turned out to be much more inventive than a man who, unfortunately, was unprepared to receive such dangerous and uninvited guests. 
The problem of biotic relations between a microbe and a body under conditions of the host immunosuppression at all times will remain the Alpha and the Omega of internal medicine.

\section{Acknowledgments}

This study is devoted to the blessed memory of the prominent cardiac surgeon, a co-founder of the national cardiac surgery, academician E.N. Meshalkin; to the Head of the Septic Endocarditis Department of the Surgery Division for Acquired Heart Valvular Diseases, Candidate of Medical Sciences, cardiac surgeon L.A. Devyatyarov; the Head of the Pathomorphology Department, Professor G.G. Chasovskikh; the cardiac surgeon, Doctor of Medical Sciences V.S. Shchukin.

The authors express their profound gratitude to the cardiac surgeons: The Doctor of Medical Sciences A.M. Kozyr, the Candidate of Medical Sciences N.N. Tetyutsky, A.A. Parygin, the Candidate of Medical Sciences A.V. Baboshko, the Candidate of Medical Sciences S. I. Ivantsov; the pathomorphologists: the Candidate of Medical Sciences V.A. Gross, V.N. Illarionov, the Doctor of Medical Sciences P.M. Larionov; the Head of the Bacteriology Department, Candidate of Biological Sciences L.A. Shmerling; the doctor of functional research methods I.G. Zorina; the Candidate of Biological Sciences, geneticist N.N. Yakovchenko, for their, over the years, daily professional contribution to the creation of a database to form an idea of the "new" clinical phenomenon of the 20th and $21^{\text {st }}$ centuries Primary Chronic Septic Endocarditis - as an obligate component of a multi-component pandemic of non-cyclical infections of the $21^{\text {st }}$ century.

\section{References}

1. Mitrofanova LB (2007) Valvular heart defects. A new look at etiology, pathogenesis, morphology. Medical publishing house. St. Petersburg 192.

2. Storozhakov GI, Gendlin GE, Miller OA (2015) Data from the National Medical Research Center for Cardiovascular Surgery named after AN Bakulev, 2001. Quoted from Heart valve disease. Praktika Publishing House. Moscow 198.

3. Storozhakov GI, Gendlin GE, Miller OA (2015) Heart valve disease. Praktika Publishing House M 198.

4. Meshalkin EN, Bushmanova GM (1986) Chronic septic endocarditis is a new topical problem in internal medicine. Septic endocarditis in heart disease surgery. Novosibirsk: Nauka 3-13.

5. Meshalkin EN, Bushmanova GM (1987) Chronic septic endocarditis is an urgent problem in cardiac surgery. Septic endocarditis in heart disease surgery. Novosibirsk 2-6.

6. Gross VA (1991) Pathomorphology of chronic endocarditis in cardiac patients. Thesis of Candidate of Medical Science. Novosibirsk: Institute of Clinical and Experimental Medicine.

7. Bushmanova GM, Devyatyarov LA, Kozyr AM, Schukin VS (1994) Rheumatism and chronic septic endocarditis. Arguments in favour and against". Pathology of the cardiovascular system and cardiac surgery strategy. Novosibirsk 146150 .

8. Larionov PM, Chasovskikh GG, Bushmanova GM, Gorbatykh YuN, Kozyr AM et al. (1995) Diagnosing method for the stages of bacterial endocarditis. Novosibirsk Scientific Research Institute of Circulatory Pathology.
9. Bushmanova GM, Supotnitsky MV (2016) Primary chronic septic endocarditis as one of the clinical guise of a multicomponent pandemic of a non-cyclic type. Collection of materials of the $11^{\text {th }}$ National Congress of Therapists. M: Design Market: Bionika-Media LLC 25.

10. Bushmanova GM, Supotnitsky MV, Devyatyarov LA, Kozyr AM, Gross VA, et al. (2017) The "new" clinical phenomenon of the $20^{\text {th }}-21^{\text {st }}$ centuries - primary chronic septic endocarditis as an argument against rheumatism XII National Congress of Therapists. M: Design Market: Bionika-Media LLC.

11. Bushmanova GM (2019) Latent primary chronic endocarditis from the perspective of prominent representatives of Russian medicine of the past and the results of long-term study of primary chronic septic endocarditis (1980-2019). $5^{\text {th }}$ Congress of Physicians of the Volga Federal District. Nizhny Novgorod 44-45.

12. Bushmanova GM (2019) Viruses as possible "initiators" of primary chronic septic endocarditis. $14^{\text {th }}$ National Congress of Physicians (with international participation). Moscow 106.

13. Bushmanova GM, Zorina IG, Terletsky AV, Akhmerova LG (2020) The "new" clinical phenomenon of the $20^{\text {th }}-21^{\text {st }}$ centuries - primary chronic septic endocarditis as an argument against the diagnosis of "rheumatism". Journal Therapy 2: 34-45.

14. Deyatyarov LA, Kozyr AM, Bushmanova GM, et al. (1987) Hospital, clinical, bacteriological and morphological assessment of primary chronic septic endocarditis in patients with acquired valvular heart disease. Novosibirsk: Nauka 38-43.

15. Bushmanova GM (1987) The main clinical extracardial markers of chronic sepsis and endocarditis. Septic endocarditis in heart disease surgery. Novosibirsk: Nauka 9-15.

16. Bushmanova GM (1989) The main issues in the diagnosis of chronic septic endocarditis. Septic endocarditis in heart disease surgery. Novosibirsk Book Publishing House 8-21.

17. Bushmanova GM (2016) Possibilities of early diagnosis of septic endocarditis at different historical stages of cognition of the disease and primary chronic septic endocarditis, as a basis for changing diagnostic priorities. II Russian Congress with international experts Proliferative Syndrome in Biology and Medicine. M 237-245

18. Bushmanova GM, Zorina IG, Ostankovich OI (2013) From isolated parietal endocarditis to mitral stenosis. Path in 29 years. VIII National Congress of Therapists. Collection of materials M 53-54.

19. Bushmanova GM, Zorina IG, Ostankovich OI (2018) Primary chronic septic parietal endocarditis, as part of a long-term prospective observation of the patient, 35 years later. IV Eurasian Congress of Rheumatologists. M. Scientific and practical rheumatology 56: 24 .

20. Bushmanova GM, Zorina IG, Ostankovich OI (2018) The history of progression of parietal primary chronic septic endocarditis, as part of a prospective observation of a patient (1985-2018). VI Congress of Physicians of Siberia. Novosibirsk 49

21. Bushmanova GM (2019) Progressive initially parietal primary chronic septic endocarditis against the background of irregular examination. $4^{\text {th }}$ Congress of Physicians of the Southern Federal District. Rostov-on-Don 82-83.

22. Bushmanova GM, Zorina IG (2019) Dynamics of the formation of a three-valve lesion in a patient with initial parietal septic endocarditis (1990-2019). $5^{\text {th }}$ Congress of Physicians of the Volga Federal District. Nizhny Novgorod 45.

23. Bushmanova GM, Zorina IG (2019) Initial parietal primary chronic septic endocarditis as a cause of heart disease developing in a patient. $2 \mathrm{~d}$ Congress of therapists of the Far East. Khabarovsk 38-39.

24. Bushmanova GM, Zorina IG (2019) Peculiarities of primary chronic septic to valvular endocarditis in patient A.E., 26 years old (1986-2019). 2d Congress of therapists of the Far East. Khabarovsk 39-40.

25. Larionov PM (1993) Morphologic changes in chronic septic endocarditis in patients with acquired valvular heart disease. Thesis of Candidate of

Citation: Bushmanova GM, Supotnitskiy MV, Churin BV (2020) Primary chronic septic endocarditis as an alternative to acute rheumatic fever - the obligate component of the multicomponent noncyclic pandemic of the $21^{\text {st }}$ Century. J Cardiovasc Med Cardiol 7(3): 242-248.DOI: https://dx.doi.org/10.17352/2455-2976.000146 
Medical Science. Novosibirsk: Institute of Regional Pathology and Pathologic Morphology.

26. Terletskiy AV, Akhmerova LG (2009) Method of diagnosis of blood parasitic diseases. Novosibirsk: SHI-KON LLC.

27. Zalessky GD (1959) New in the doctrine of the pathogenesis of rheumatism Rheumatism and parasitic diseases. Materials of the All-Russian Conference of Therapists. Novosibirsk: Novosibirsk Book Publishing House 51-59.

28. Yavorovskaya VE, Saratikov AS, Blagherman SK, Evstropov AN, Prishchep TP (1962) Rheumatism. Issues of etiology and pharmacotherapy. Publishing house of Tomsk University. Tomsk 4: 62-89.

29. Warren K (1978) Quotes by V.S. Paukova and O.Ya. Kaufman. Inflammation Guide. M: Medicine 190

30. Epstein WL (1980) Quotes by V.S. Paukova and O.Ya. Kaufman. Inflammation Guide. M: Medicine 190

31. Bushmanova GM, Gross VA (2019) Aschoff-Talalaev granuloma to meet its $115^{\text {th }}$ anniversary: For or against rheumatic fever. $14^{\text {th }}$ National Congress of Physicians (with international participation). Moscow 106-107.

32. Anokhin VN (1993) Diagnostic criteria for rheumatic fever in clinical practice. Abstracts of the First Congress of Rheumatologists of Russia. Modern problems of rheumatology. Orenburg 29-30.

33. Strazhesko ND (1956) Selected works 2. The problem of sepsis, endocarditis, rheumatism. Publishing house of the Academy of Sciences of the Ukrainian SSR. Kiev 368.

34. Belyaev AM, Larionov PM (1998) A method for modeling infective endocarditis. Invention patent RU $2109524 \mathrm{Cl}, 24.04 .1998$.

35. Bilibin AF (1972) Clinical chemotherapy is a problem of endogenous infections. Moscow.

36. Bushmanova GM, Nepomnyashchikh LM (2014) Primary chronic septic endocarditis as a possible tragedy of the intrapartum period of development, the initial viral infection. Translational medicine (disk): theses of the IX International scientific-practical conference "Sudden death: from risk criteria to prevention." St. Petersburg

37. Bushmanova GM, Terletsky AV, Akhmerova LG (2007) Primary chronic septic endocarditis and blood parasite diseases. A new clinical phenomenon of 20 $21^{\text {st }}$ centuries. International Proceedings of the V European Astma Congress and I World Congress on COPD. Moskow: Bologne MEDIMOND International Proceedings 59-62.

38. Bushmanova GM, Terletskiy AV, Akhmerova LG, Guseva IA (2007) Causeand-effect relations between cardiac arrhythmias and primary chronic septic endocarditis associated with blood parasitic infections. Allergology and Immunology 8: 259 .

39. Terletsky AV, Akhmerova LG, Evtushenko EV (2019) Blood parasite infection causing inflammatory reactions and benign formations in human thyroid gland. Infektsiya i immunitet 9: 155-161. Link: https://bit.ly/30HUDw2

40. Bushmanova GM, Zorina IG, Nepomnyashchikh LM, Supotnitskiy MV (2016) Primary chronic septic endocarditis as progressive fibroplastic process. 5th Congress of therapists of Siberia and Far East. Novosibirsk: KST Unterforum LLC 54-55.

41. Davies MJ (1980) Pathology of cardiac valves. London: Butterworth. 180.

42. Zorina IG, Bushmanova GM, Nepomnyashchikh LM (2013) Early echocardiographic manifestations of primary chronic septic endocarditis. Allergy, Asthma \& Immunophysiology: from basic science to clinical management. Proceedings of the $4^{\text {th }}$ World Asthma, Allergy \& COPD Forum and $18^{\text {th }}$ International Congress on Immunoreabilitation and Reabilitation in Medicine. London (UK): MEDIMOND International Proceedings. 189-191.
43. Zorina IG, Bushmanova GM (2014) Early echocardiographic manifestations of primary chronic septic endocarditis. Bulletin of Experimental Biology and Medicine 2: 241-245. Link: https://bit.ly/2XL97cr

44. Bushmanova GM, Zorina IG (2018) Working clinical-morpho-topographic classification of primary chronic septic endocarditis. 3d Russian Congress with International Participation "Proliferative Syndrome in Biology and Medicine" Materials of the Congress. M 343-352.

45. Aagaard K, Riehle K, Ma J, Segata N, Mistretta TA, Coarfa C, et al. (2012) A metagenomic approach to characterization of the vaginal microbiome signature in pregnancy. PLoS One 7: e36466. Link: https://bit.ly/2DFyl5o

46. Bushtyreva IO, Bushtyrev VA, Barinova VV, Kuznetsova NB (2018) Microbiome of the female reproductive system: there are more questions than answers. Glavny Vrach 3: 49-52.

47. Rautava S, Collado MC, Salminen S, Isolauri E (2012) Probiotics modulate host-microbe interaction in the placenta and fetal gut: a randomized, doubleblind, placebo-controlled trial. Neonatology 102: 178-184. Link: https://bit. ly/30ILhjl

48. Zaura E, Nicu EA, Krom BP, Keijser BJ (2014) Acquiring and maintaining a normal oral microbiome: current perspective. Front Cell Infect Microbiol 4: 85 Link: https://bit.ly/3iv0I5a

49. Romero R, Miranda J, Kusanovic JP, Chaiworapongsa T, Chaemsaithong $P$ et al. (2015) Clinical chorioamnionitis at term I: microbiology of the amniotic cavity using cultivation and molecular techniques. J Perinat Med 43: 19-36. Link: https://bit.ly/3kwmAP

50. Aagaard K, Ma J, Antony KM, Ganu R, Petrosino J, Versalovic J (2014) The Placenta harbors a unique microbiome. Sci Transl Med 6: 237ra65.

51. Loohuis LMO, Mangul S, Ori APS, Jospin G, Koslicki D, et al. (2018) Transcriptome analysis in whole blood reveals increased microbial diversity in schizophrenia. Transl Psychiatry 8: 96. Link: https://go.nature.com/2DJ8IG6

52. Moreno I, Codoñer FM, Vilella F, Valbuena D, Martinez-Blanch JF, et al. (2016) Evidence that the endometrial microbiota has an effect on implantation success or failure. Am J Obstet Gynecol 215: 684-703. Link: https://bit. ly/2PGSNFh

53. Ivashkin VT, Ivashkin KV (2017) Human microbiome as an application to clinical practice, Russian Journal of Gastroenterology Hepatology Coloproctology 27 4-10.

54. Goltsman DSA, Sun LC, Proctor DM, DiGiulio DB, Robaczewska A, et al. (2020) Metagenomic analysis with strain-level resolution reveals fine-scale variation in the human pregnancy microbiome. Genome Res 28: 1467-1480. Link: https://bit.ly/2PJWc6p

55. Supotnitskiy MV (2000) Microorganisms, toxins and epidemic. M.: Vuzovskaya kniga 376.

56. Supotnitskiy MV (2009) Evolutionary pathology. To the question of the place of HIV infection and HIV/AIDS pandemic among other infectious, epidemic and pandemic processes. M.: University book 400.

57. Bushmanova GM, Supotnitskiy MV (2016) Primary chronic septic endocarditis as one of the clinical guises of the non-cyclic multicomponent pandemic. M 25. Design Market: Bionika-Media LLC.

58. Bushmanova GM, Supotnitskiy MV (2016) Clinical guises of the chronic HSV sepsis pandemic. 2d Russian Congress with international experts "Proliferate Syndrome in Biology and Medicine M 246-251.

59. Bushmanova GM, Supotnitskiy MV (2020) The COVID-19 pandemic is one of the components of the multicomponent pandemic of the $21^{\text {st }}$ Century. Cardiovasc Med Cardiol 7: 163-166. Link: https://bit.ly/3aOzfZy

Copyright: (c) 2020 Bushmanova GM, et al. This is an open-access article distributed under the terms of the Creative Commons Attribution License, which permits unrestricted use, distribution, and reproduction in any medium, provided the original author and source are credited.

Citation: Bushmanova GM, Supotnitskiy MV, Churin BV (2020) Primary chronic septic endocarditis as an alternative to acute rheumatic fever - the obligate component of the multicomponent noncyclic pandemic of the $21^{\text {st }}$ Century. J Cardiovasc Med Cardiol 7(3): 242-248.DOI: https://dx.doi.org/10.17352/2455-2976.000146 